\title{
Development and Validation of Amlodipine Impurities in Amlodipine Tablets Using Design Space Computer Modeling
}

\author{
Chamarthi R. P. Kishore*, G. V. Krishna Mohan \\ Department of Chemistry, K.L. University, Vaddeswaram, India \\ Email: *phanikishore82@gmail.com
}

How to cite this paper: Kishore, C.R.P. and Mohan, G.V.K. (2016) Development and Validation of Amlodipine Impurities in Amlodipine Tablets Using Design Space Computer Modeling. American Journal of Analytical Chemistry, 7, 918-926.

http://dx.doi.org/10.4236/ajac.2016.712078

Received: July 6, 2016

Accepted: December 25, 2016

Published: December 28, 2016

Copyright $\odot 2016$ by authors and Scientific Research Publishing Inc. This work is licensed under the Creative Commons Attribution International License (CC BY 4.0).

http://creativecommons.org/licenses/by/4.0/

\begin{abstract}
A rapid, sensitive, robust, rugged and linear HPLC method is developed using QbD approach and validated as per ICH for the estimation of amlodipine impurities in tablet dosage form. Phosphate buffer with triethyl amine adjusted to $\mathrm{pH}$ to 2.8 is used as the mobile phase and $3 \mu$ particle size C18 column of $150 \mathrm{~mm}$ length and 4.6 $\mathrm{mm}$ internal diameter is used. Using photo diode array (PDA) detector, the compounds are monitored at $340 \mathrm{~nm}$. All impurities are well separated and flow Gradient has been optimized to obtain the acceptable resolution between impurities and amlodipine. Diluent was chosen, based on the impurity peak shapes and recoveries. Test concentration and injection volume have been optimized to obtain limit of quantification (LOQ) values below the reporting threshold.
\end{abstract}

\section{Keywords}

HPLC, LOQ, QbD, Reporting Threshold

\section{Introduction}

Amlodipine (chemically known as (RS)-3-ethyl 5-methyl

2-[(2-aminoethoxy)methyl]-4-(2-chlorophenyl)-6-methyl-1,4-dihydropyridine-3,5-dica rboxylate with molecular formulae $\mathrm{C}_{20} \mathrm{H}_{25} \mathrm{ClN}_{2} \mathrm{O}_{5}$ and molecular weight of $408.9 \mathrm{~g} / \mathrm{mol}$ ) is used to treat the high blood pressure by allowing the free flowing of blood through blood cells. Amlodipine belongs to calcium channel blocker group. Many pharma companies are formulating and marketing amlodipine as single or in combination with other active ingredients under different brand names like Asomex, Istin, Norvasc, Caduet and Twynsta. Stability studies provide us with information on the quality of the 
drug product. The studies must include the tests, which can monitor the quality of the drug product [1]. Impurities can be generated by drug excipient interactions, storage conditions, hydrolysis etc. A sensitive, reproducible method is to be developed and validated to monitor the impurities in drug product.

Literature survey reveals that some analytical methods are available for the estimation of amlodipine alone or in combination with other drugs using HPLC, HPTLC, and LC-MS [2]-[13]. Ph. Eur monograph method is also reported to estimate impurities in amlodipine besylate raw material. However, none of the analytical methods reported the estimation of all known and unknown impurities for amlodipine besylate. This paper describes the quantification of all impurities (IMP-A, IMP-B, IMP-D, IMP-E, IMP-F, IMP-G and IMP-H) of amlodipine besylate in amlodipine tablets.

\section{Materials and Methods}

\subsection{Chemicals and Reagents}

Amlodipine besylate tablets and all impurities were synthesized and supplied by Dr. Reddy's Laboratories Ltd. Potassium dihydrogen phosphate, triethyl amine, orthophosphoric acid of AR grade and methanol and acetonitrile of gradient grade were purchased from Merck Chemicals Ltd.

\subsection{Chromatographic Conditions}

The mixed buffer was prepared by adding $7 \mathrm{ml}$ of triethyl amine to $1000 \mathrm{ml}$ of $50 \mathrm{~mm}$ monobasic phosphate buffer and then the $\mathrm{pH}$ was adjusted to 2.8 with orthophosphoric acid. Mobile phase-A was prepared by mixing the buffer with methanol in the ration of 60:40 (v/v) while Mobile phase-B was prepared by mixing the buffer with methanol and acetonitrile in the ratio of 20:40:40 (v/v/v). Mobile phase-A contains more buffer concentration to separate all impurities. Mobile phase-B contains more organic concentration to elute all the impurities.

A column with $150 \mathrm{~mm}$ length, $4.6 \mathrm{~mm}$ internal diameter and $3 \mu$ particle sizes, C18 as stationary phase was used to separate all the impurities. Column temperature was maintained at $35^{\circ} \mathrm{C}$. All impurities were monitored at $340 \mathrm{~nm}$ except impurity-D. Impurity-D was monitored at $270 \mathrm{~nm}$. Gradient mode flow was used to separate the impurities. Flow rate of the mobile phase was kept at $1.0 \mathrm{~mL} / \mathrm{min}$ and $100 \mu \mathrm{L}$ samples were injected into HPLC. Analysis was performed on Waters HPLC system with PDA detector. The diluent for extraction of impurities and amlodipine from formulation matrix was prepared by admixing Buffer, Methanol and acetonitrile in the ratio of 70:15:15 (v/v/v).

\subsection{Solution Preparations}

\subsubsection{Standard Stock Preparation}

$70 \mathrm{mg}$ of amlodipine besylate standard (potency-72\%) was weighed and transferred into $250 \mathrm{~mL}$ of volumetric flask and it was dissolved and diluted to volume with methanol. $5 \mathrm{~mL}$ of this solution was diluted to $100 \mathrm{~mL}$ with methanol. 
2.3.2. Final Standard Stock Preparation

$5 \mathrm{~mL}$ of the standard stock solution was diluted to $100 \mathrm{~mL}$ with diluent.

\subsubsection{Sample Preparation}

20 tablets were crushed into fine powder and then the powder equivalent to $25 \mathrm{mg}$ of amlodipine was transferred into $100 \mathrm{ml}$ volumetric flask and then $70 \mathrm{ml}$ of diluent was added. The resulting solution was sonicated for 30 minutes with intermittent shaking and the temperature of the sonication was maintained below $25^{\circ} \mathrm{C}$. Then the solution was diluted to the volume with the diluent and was centrifuged the sample at 4000 RPM for 15 mins and then few $\mathrm{ml}$ of the supernatant solution was filtered through $0.45 \mu$ membrane filter.

\subsubsection{Impurity Stock Solution Preparation}

$2 \mathrm{mg}$ of each impurity was weighed, transferred to $20 \mathrm{ml}$ volumetric flask and then dissolved in methanol and the resulting solution was diluted to the mark.

\subsubsection{Spiked Sample Preparation}

Tablet powder equivalent to $25 \mathrm{mg}$ of amlodipine was weighed and transferred into $100 \mathrm{~mL}$ volumetric flask. $70 \mathrm{ml}$ of the diluent was added. Then, $1.25 \mathrm{~mL}$ of impurity stock solution was added. The resulting solution was sonicated for $30 \mathrm{mins}$ and then diluted to volume with the diluent. Then the solution was centrifuged at 4000 RPM for 15 mins and filtered the few $\mathrm{ml}$ of the supernatant solution through $0.45 \mu \mathrm{mem}$ brane filter.

\subsection{Analytical Method Validation}

The developed method was validated as per ICH guidelines for specificity, linearity, precision, ruggedness and robustness.

\section{Results and Discussion}

\subsection{Optimization of Chromatographic Conditions}

Different trials were taken with mobile phases containing ammonium salts, phosphate and sodium perchlorate buffers to obtain optimum resolution between impurities. Final chromatographic conditions were finalized based on the DOE. Fractional design was used to perform DOE by considering the flow rate, $\mathrm{pH}$ of the buffer, $\%$ methanol and $\%$ acetonitrile in mobile phase- $\mathrm{B}$ as factors and resolution between the close eluting impurities (Impurity-B \& $\mathrm{H}$ ) as responses. A text plan was shown in Table 1 using 10 combinations of the factors used for evaluation study.

The obtained results were transcribed back into Minitab software for modelling purposes. The effects of factors on resolutions were evaluated using Mini tab software generated three-dimensional plots and Pareto chart. Figure 1 represents main effects plot for the resolution between Imp-B\&H. Figure 2 represents interaction plot, Figure 3 represents pareto chart for standardized effects and Figure 4 represents contour plot for resolution. Flow rate and \% acetonitrile play major role in separation of impurities. 
Table 1. Design of experiments.

\begin{tabular}{cccccccc}
\hline Std Order & Run Order & Center Pt & Flow & pH & \% MeOH & \% ACN & Resolution b/w B \& H \\
\hline 1 & 1 & 1 & 0.8 & 2.6 & 35 & 35 & 1.765 \\
2 & 2 & 1 & 1.2 & 2.6 & 35 & 45 & 2.951 \\
3 & 3 & 1 & 0.8 & 3.0 & 35 & 45 & 1.774 \\
4 & 4 & 1 & 1.2 & 3.0 & 35 & 35 & 2.613 \\
5 & 5 & 1 & 0.8 & 2.6 & 45 & 45 & 1.806 \\
6 & 6 & 1 & 1.2 & 2.6 & 45 & 35 & 2.706 \\
7 & 7 & 1 & 0.8 & 3.0 & 45 & 35 & 1.611 \\
8 & 8 & 1 & 1.2 & 3.0 & 45 & 45 & 2.813 \\
9 & 9 & 0 & 1.0 & 2.8 & 40 & 40 & 2.232 \\
10 & 10 & 0 & 1.0 & 2.8 & 40 & 40 & 2.212 \\
\hline
\end{tabular}

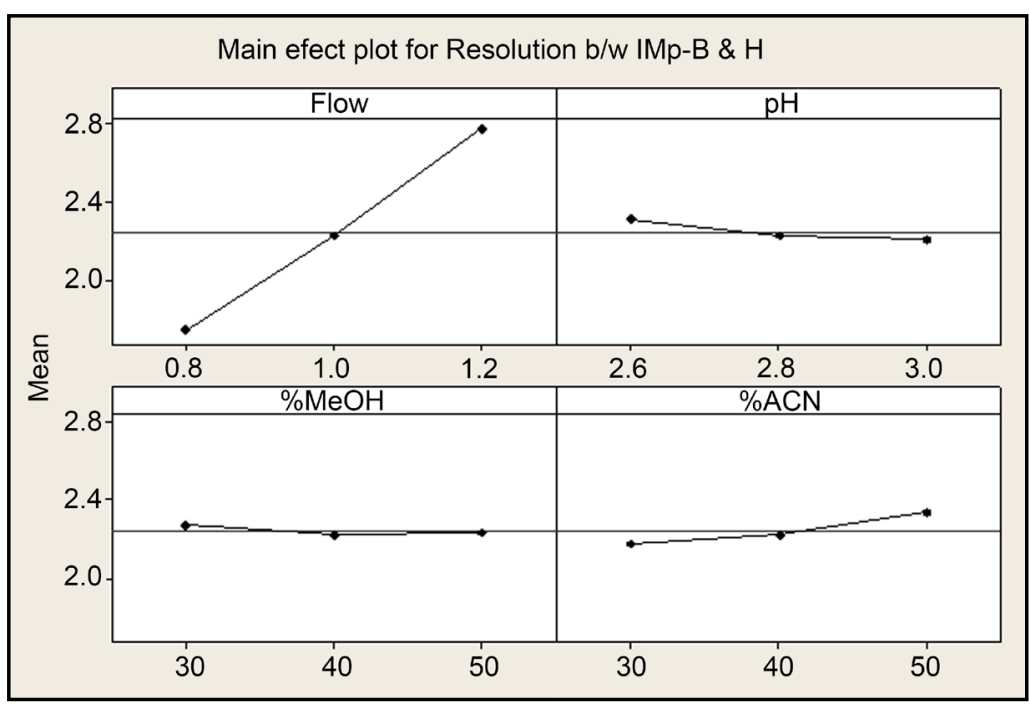

Figure 1. The main effect chart for the resolution between Imp-B \& H.

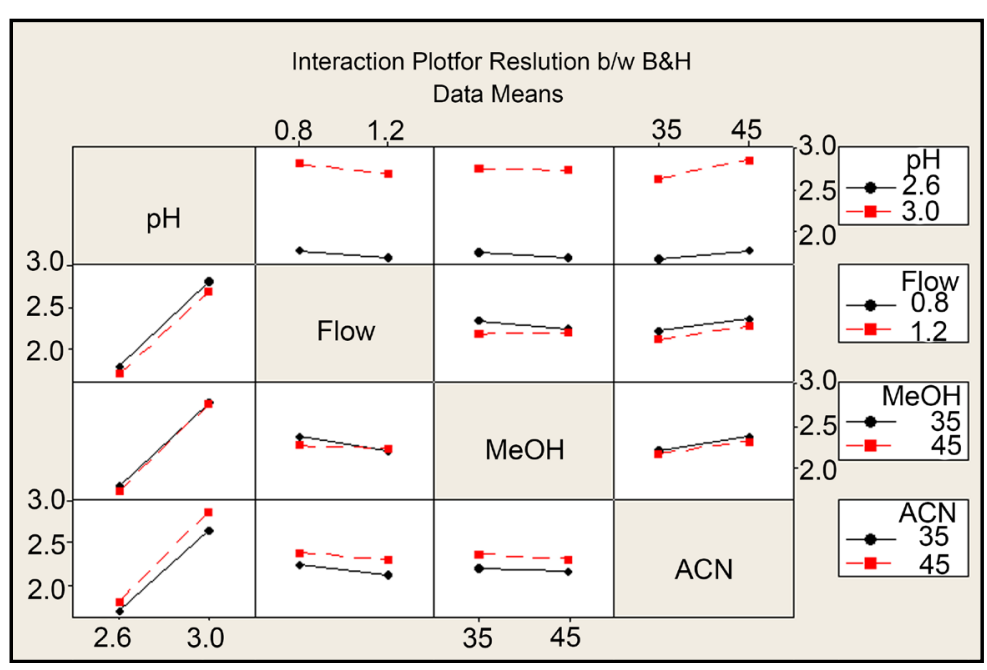

Figure 2. The interaction plot for the resolution between Imp-B \& H. 


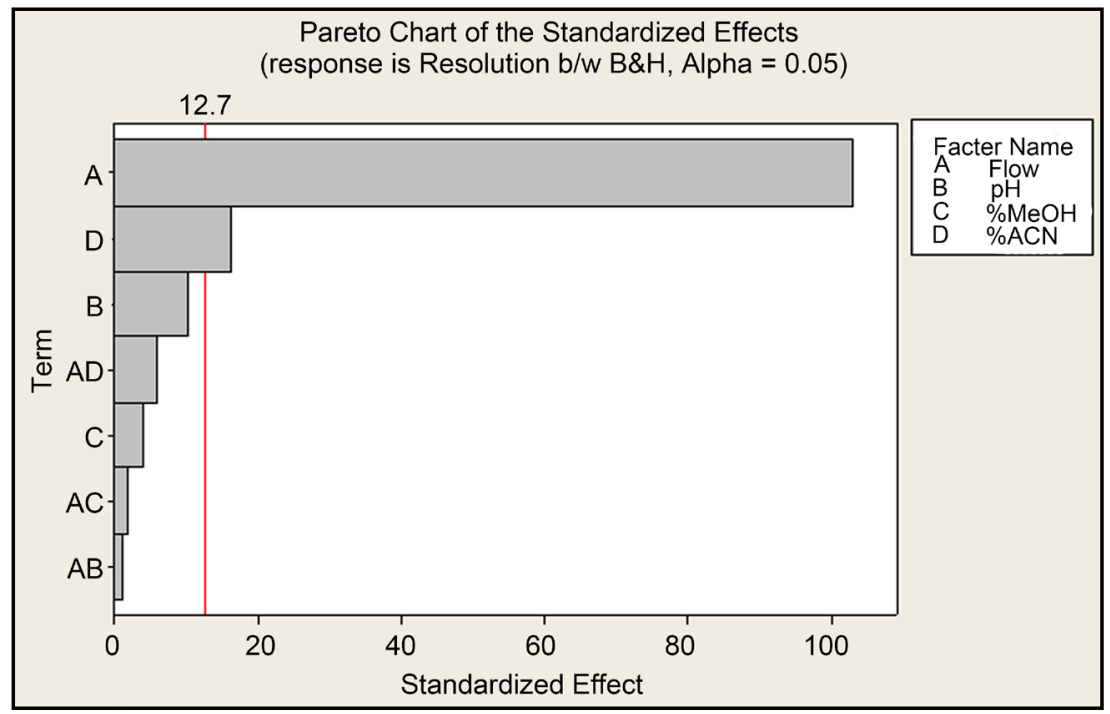

Figure 3. The Pareto chart for standardized effects on the resolution between Imp-B \& H.

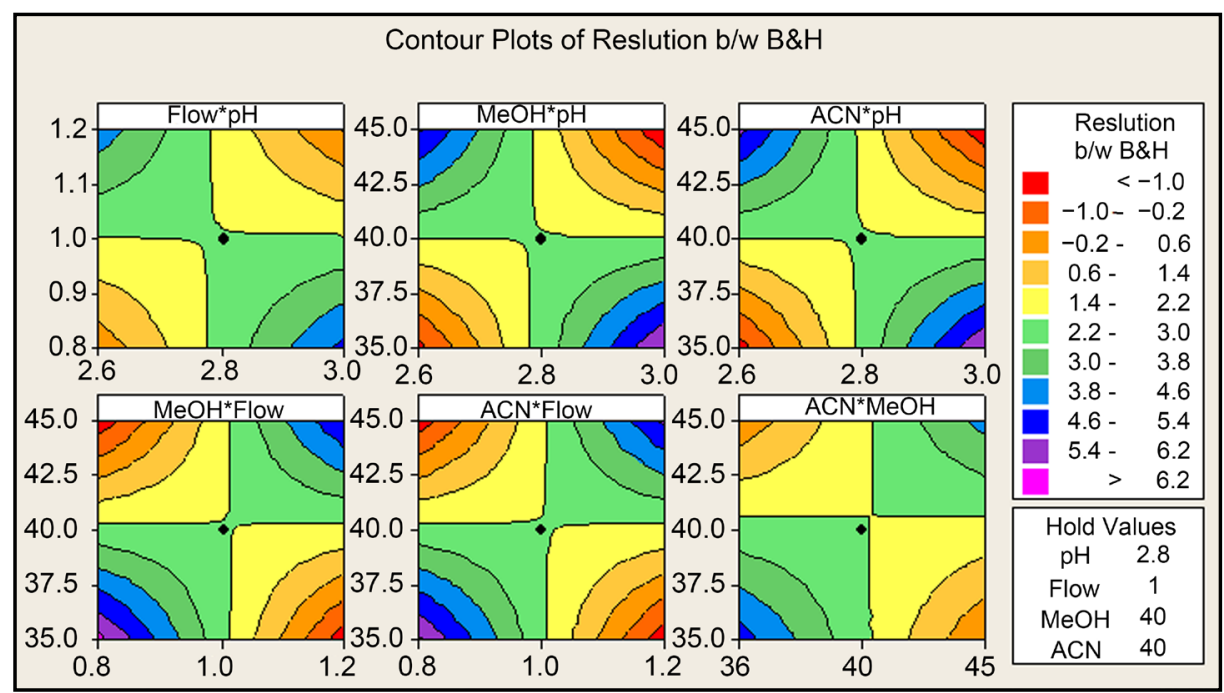

Figure 4. The contour plot for the resolution between Imp-B \& H.

Design space was established and recommended parameters were near to the experimentally proposed values. The Proposed HPLC method was shown in Table 2.

Further, experimentally obtained data were used in setting the lower and upper bounds for each response variables. Using modelled data, visual inspections of interactive effects were performed from multiple overlay graphs plotting two parameters at a time.

Diluent was finalized based on recovery and peak shape. Injection volume and test concentrations were optimized to have LOQ value less than reporting threshold. Gradient was optimized to get optimal resolution between all impurities and main analyte. Figure 5 represents the chromatogram for standard, Figure 6 represents chromatogram for spiked sample at $340 \mathrm{~nm}$ and Figure 7 represents chromatogram for spiked sample preparation at $270 \mathrm{~nm}$. 
Table 2. HPLC method conditions.

\begin{tabular}{cc}
\hline Column & \multicolumn{1}{c}{ Inertsil ODS-3, $150 \times 4.6 \mathrm{~mm} 3 \mu$} \\
\hline $\begin{array}{c}\text { Column temperature } \\
\text { Wave length } \\
\text { Injection volume } \\
\text { Run time }\end{array}$ & $270 \mathrm{~nm}$ for Imp-D and $340 \mathrm{~nm}$ for remaining impurities \\
& $100 \mu \mathrm{L}$ \\
& 70 minutes \\
& $90 \%$ A upto 8 min (isocratic) with $1.0 \mathrm{~mL}$ \\
& Linear gradient to $75 \%$ A at 20 min with $1.0 \mathrm{~mL}$ \\
Linear gradient to $70 \%$ A at 45 min with $1.0 \mathrm{~mL}$ & Linear gradient to $20 \%$ A at 50 min with $1.2 \mathrm{~mL}$ \\
Linear gradient to $0 \%$ A at 52 min with $1.2 \mathrm{~mL}$ \\
$0 \%$ A from 52 min to 60 min with $1.2 \mathrm{~mL}$ \\
Linear gradient to $90 \%$ A at 62 min with $1.0 \mathrm{~mL}$ \\
$90 \%$ A from 62 min to 70 min with $1.0 \mathrm{~mL}$ \\
\hline
\end{tabular}

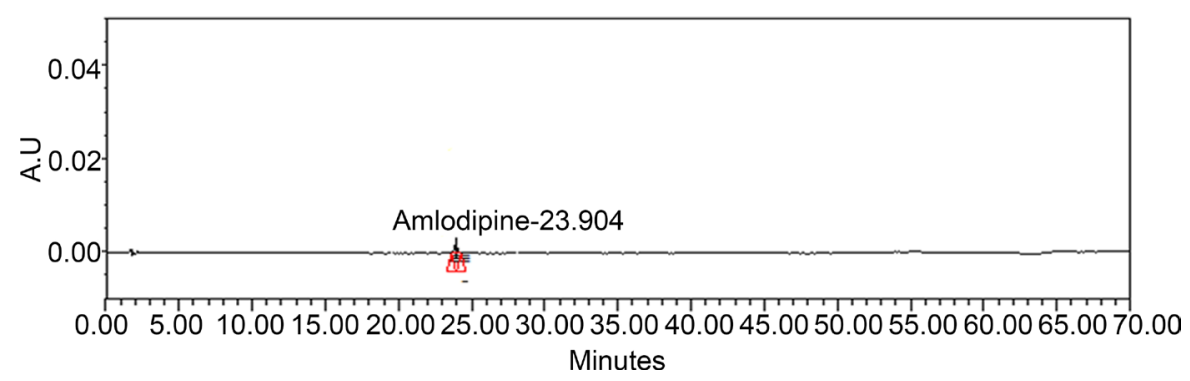

Figure 5. The chromatogram for standard preparation.

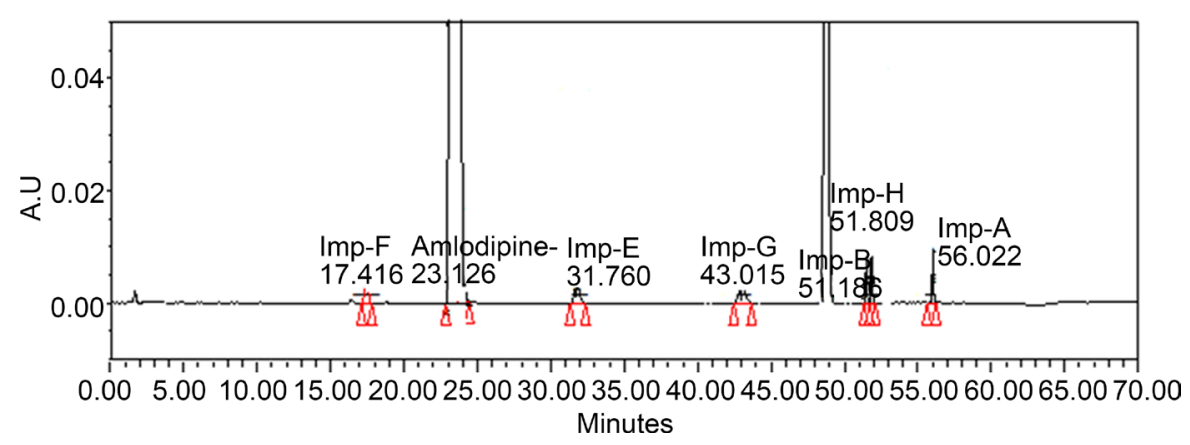

Figure 6. The chromatogram for sample preparation at $340 \mathrm{~nm}$.

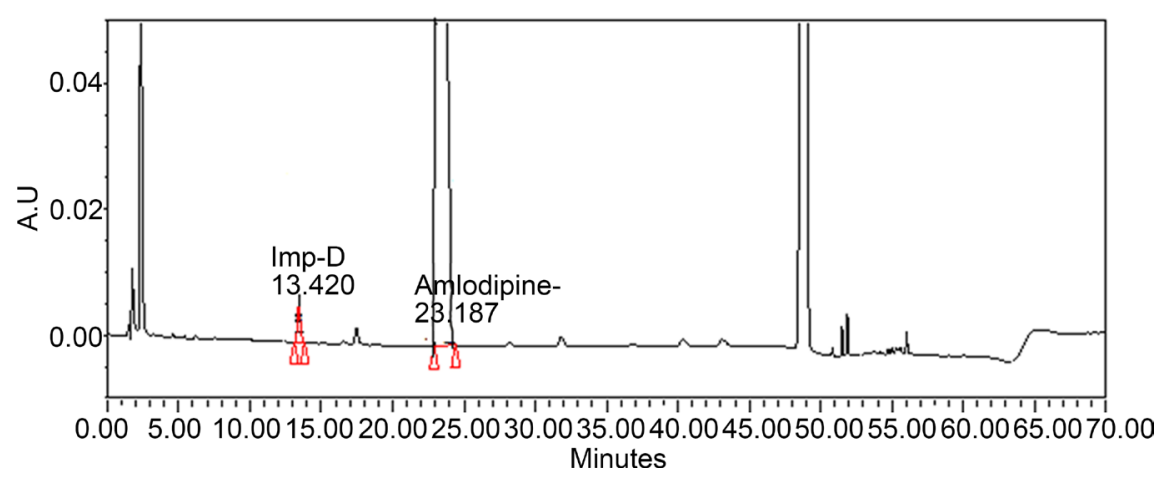

Figure 7. The chromatogram for sample preparation at $270 \mathrm{~nm}$. 


\subsection{Method Validation}

\subsubsection{System Suitability}

The authors prepared the standard at $0.2 \%$ level of the test concentration and injected it into HPLC system; and then calculated the \% RSD for peak areas, USP plate count, tailing factor of amlodipine peak from replicate standard injections. \% RSD from replicate injections was found to be 3.2. The tailing factor for main analyte is found to be 1.0 and plate count is found to be 43685 . Results are tabulated in Table 3. Resolution between Impurity-B and Impurity-H was found to be 2.7 .

\subsubsection{Linearity and Range}

Linearity was established over the range of $0.0001 \mathrm{mg} / \mathrm{ml}$ to $0.05 \mathrm{mg} / \mathrm{ml}$ for all the impurities and main analyte. Six different linearity solutions were prepared and injected into system. Results are tabulated in Table 4.

\subsubsection{Specificity}

Test samples were subjected to different stress conditions like acid, base, water hydrolysis, peroxide oxidation, thermal degradation, sun light/UV degradation and Humidity degradation. Sample was exposed to acidic $(0.1 \mathrm{~N} \mathrm{HCl} / 5 \mathrm{~mL} / 30 \mathrm{~min}$ reflux), alkaline $(0.1 \mathrm{~N} \mathrm{NaOH} / 5 \mathrm{~mL} / 60 \mathrm{~min}$ reflux $)$, Oxidation $\left(\% 5 \mathrm{H}_{2} \mathrm{O}_{2} / 10 \mathrm{~mL} / 30 \mathrm{~min}\right.$ reflux $)$, thermal $\left(105^{\circ} \mathrm{C} / 24 \mathrm{hrs}\right)$, water $\left(10 \mathrm{~mL} / 60^{\circ} \mathrm{C} / 30 \mathrm{~min}\right.$ reflux $)$ water conditions, sunlight (1.2 million lux hrs), UV light (200 watt hours) and Humidity (90\% RH for 7 days). All the samples were injected into HPLC system with PDA detector to identify the purity of the known and main analyte peaks. Purity angles were less than purity threshold for all the known impurities and amlodipine peak. The results were tabulated in Table 5. On

Table 3. System suitability parameters.

\begin{tabular}{ccc}
\hline System suitability parameters & Observation & Acceptance criteria \\
\hline Tailing factor for amlodipine peak in diluted standard preparation & 1.0 & Not more than 2.0 \\
Plate count for amlodipine peak & 43,685 & Not less than 2000 \\
\% RSD for areas of amlodipine & 3.2 & Not more than 3.0 \\
Resolution between Imp-B and Imp-H & 2.7 & Not less than 2.0 \\
\hline
\end{tabular}

Table 4. LOD, LOQ, linearity, precision and recovery values.

\begin{tabular}{cccccccc}
\hline Parameters & Imp-A & Imp-B & Imp-D & Imp-E & Imp-F & Imp-G & Imp-H \\
\hline LOQ (ppm) & 0.095 & 0.11 & 0.09 & 0.15 & 0.10 & 0.15 \\
LOD (ppm) & 0.031 & 0.06 & 0.03 & 0.06 & 0.04 & 0.06 \\
Precision & $92.3-104.7$ & $93.7-105.9$ & $97.1-101.4$ & $98.1-105.4$ & $93.7-107.8$ & $94.9-106.0$ & $93.6-102.8$ \\
& & & & & \\
LOQ & $89.5-107.4$ & $95.3-111.6$ & $98.3-101.6$ & $88.3-95.0$ & $95.0-100.0$ & $90.0-93.4$ & $91.7-112.5$ \\
$50 \%$ & 97.4 & 100.3 & 100.7 & 105.6 & 107.1 & 99.4 \\
$100 \%$ & 87.0 & 101.5 & 92.6 & 96.7 & 107.9 & 109.7 \\
$150 \%$ & 89.6 & 99.8 & 96.4 & 97.2 & 108.7 & 99.6 & 109.9 \\
\hline
\end{tabular}


Table 5. Summary of peak purity and degradation data for amlodipine in stress study.

\begin{tabular}{cccc}
\hline Stress condition & Purity angle & Purity threshold & \% Degradation \\
\hline Acid degradation $(0.1 \mathrm{~N} \mathrm{HCl} / 1$ hr reflux $)$ & 0.080 & 0.694 & 3.79 \\
Base degradation & 0.088 & 0.610 & 3.62 \\
$\left(\begin{array}{c}\mathrm{N} \mathrm{NaOH} / 20 \text { min reflux }) \\
\text { Peroxide degradation }\end{array}\right.$ & 0.109 & 0.663 & 0.79 \\
$\left(10 \% \mathrm{H}_{2} \mathrm{O}_{2} / 20\right.$ min reflux $)$ & 0.090 & 0.684 & 0.56 \\
Thermal $\left(105^{\circ} \mathrm{C} / 72\right.$ hrs/solid $)$ & 0.114 & 0.617 & 3.87 \\
Water & 0.102 & 0.626 & 0.73 \\
Sun light/UV light & 0.108 & 0.598 & 0.41 \\
\hline Humidity & &
\end{tabular}

perusal of the results, it may be concluded that all the unknown impurities generated in the degradation are well separated from the known and amlodipine peaks. Hence, the developed method is specific.

\subsubsection{Precision and Accuracy}

Recovery studies were performed for all the impurities from $0.000125 \mathrm{mg} / \mathrm{ml}$ to $0.001875 \mathrm{mg} / \mathrm{ml}$ and values were found to be between $85 \%-110 \%$. Precision was performed by preparing six samples by spiking the impurities at $0.5 \%$ of the target test concentration. Results were tabulated in Table 4. The resultant \% RSD values for the \% impurities were found the below $5.0(n=6)$. Hence, it may be concluded that the method is precise and accurate.

\subsubsection{LOD and LOQ}

LOQ and LOD were established for the impurities and amlodipine using slope method. LOQ values were found to be 0.01 . The concentration with signal to noise ratio about three was taken as LOD and ten was taken as LOQ. Values were presented in Table 4.

\subsubsection{Mobile Phase and Solution Stability}

Mobile phase and solution stability were established over a period of 24 hours on bench top. System suitability parameters were evaluated and \% impurities were calculated against fresh standard. From the results, it may be concluded that solution and mobile phase are stable up to 24 hours on bench top.

\section{Conclusion}

A novel HPLC method has been developed for the estimation of amlodipine impurities in amlodipine tablets formulation. Placebo interference was not observed at known and unknown impurities. Method is found to be linear, precise, accurate, robust and rugged. Hence, this method can be used for the estimation of amlodipine impurities in regular as well as stability sample analysis.

\section{Acknowledgements}

The author thanks the K.L. University, Department of Chemistry for providing neces- 
sary support in completing the work.

\section{References}

[1] Stability Testing of New Drug Products and Substances Q1A(R2).

[2] Agrekar, A.P. and Powar, S.G. (2000) Simultaneous Determination of Atenolol and Amlodipine in Tablets by High-Performance Thin-Layer Chromatography. Journal of Pharmaceutical and Biomedical Analysis, 21, 1137-1142.

https://doi.org/10.1016/S0731-7085(99)00210-1

[3] Chitlange, S.S., Bagri, K. and Sakarkar, D.M. (2008) Stability Indicating RP-HPLC Method for Simultaneous Estimation of Valsartan and Amlodipine in Capsule Formulation. Asian Journal of Research in Chemistry, 7, 15-18.

[4] Chaudhri, B.G., Patel, N.M. and Shah, P.B. (2007) Stability Indicating RP-HPLC Method for Simultaneous Determination of Atorvastatin and Amlodipine from Their Combination Drug Products. Chemical and Pharmaceutical Bulletin, 55, 241-246.

https://doi.org/10.1248/cpb.55.241

[5] Bahrami, G. and Mirzaeei, S.H. (2004) Simple and Rapid HPLC Method for Determination of Amlodipine in Human Serum with Fluorescence Detection and Its Use in Pharmacokinetic Studies. Journal of Pharmaceutical and Biomedical Analysis, 36, 163-168.

https://doi.org/10.1016/j.jpba.2004.05.016

[6] http://en.wikipedia.org/wiki/Amlodipine

[7] Khan, M.R. and Jain, D. (2006) Simultaneous Spectrophotometric Determination of Atorvastatin Calcium and Amlodipine Besylate in Tablet. Indian Journal of Pharmaceutical Sciences, 68, 546-548. https://doi.org/10.4103/0250-474X.27846

[8] Malesuik, M.D., Cardoso, S.G., Bajerski, L. and Lanzanova, F.A. (2006) Determination of AML in Pharmaceutical Dosage Forms by Liquid Chromatography and Ultraviolet Spectrophotometry. Journal of AOAC International, 89, 359-364.

[9] Rajeswari, K.R., Sankar, G.G., Rao, A.L. and Sheshagirirao, J.V. (2006) RP-HPLC Method for Simultaneous Determination of Atorvastatin Calcium and Amlodipine in Tablet. Indian Journal of Pharmaceutical Sciences, 68, 275-257. https://doi.org/10.4103/0250-474X.25738

[10] Sahu, R. and Patel, V.B. (2007) Simultaneous Spectrophotometric Determination of Amlodipine Besylate and Atorvastatin Calcium in Binary Mixture. Indian Journal of Pharmaceutical Sciences, 69, 110-111. https://doi.org/10.4103/0250-474X.32119

[11] Sivakumar, T., Manavalan, R., Muralidharan, C. and Valiappan, K. (2007) An Improved HPLC Method with the Aid of a Chemometric Protocol: Simultaneous Analysis of Amlodipine and Atorvastatin in Pharmaceutical Formulations. Journal of Separation Science, 30, 3143-3153. https://doi.org/10.1002/jssc.200700148

[12] Meyyanthan, S.N. and Suresh, B. (2005) HPTLC Method for the Simultaneous Determination of AML and Benazepril in Their Formulations. Journal of Chromatographic Science, 43, 73-75. https://doi.org/10.1093/chromsci/43.2.73

[13] Feng, Y., Zhang, L., Shen, Z., Pan, F. and Zhang, Z. (2002) Analysis of AML in Human Plasma by Liquid Chromatography-Mass Spectrometry. Journal of Chromatographic Science, 40, 49-53. 
Submit or recommend next manuscript to SCIRP and we will provide best service for you:

Accepting pre-submission inquiries through Email, Facebook, LinkedIn, Twitter, etc. A wide selection of journals (inclusive of 9 subjects, more than 200 journals)

Providing 24-hour high-quality service

User-friendly online submission system

Fair and swift peer-review system

Efficient typesetting and proofreading procedure

Display of the result of downloads and visits, as well as the number of cited articles

Maximum dissemination of your research work

Submit your manuscript at: http://papersubmission.scirp.org/

Or contact ajac@scirp.org 